\title{
Estimating severity of influenza epidemics from severe acute respiratory infections (SARI) in intensive care units
}

Liselotte van Asten ${ }^{*}$ (D) Angie Luna Pinzon ${ }^{1}$, Dylan W. de Lange ${ }^{2,3}$, Evert de Jonge ${ }^{2,4}$, Frederika Dijkstra ${ }^{1}$, Sierk Marbus ${ }^{1}$, Gé A. Donker ${ }^{5}$, Wim van der Hoek ${ }^{1}$ and Nicolette F. de Keizer ${ }^{2,6}$

\begin{abstract}
Background: While influenza-like-illness (ILI) surveillance is well-organized at primary care level in Europe, few data are available on more severe cases. With retrospective data from intensive care units (ICU) we aim to fill this current knowledge gap. Using multiple parameters proposed by the World Health Organization we estimate the burden of severe acute respiratory infections (SARI) in the ICU and how this varies between influenza epidemics.

Methods: We analyzed weekly ICU admissions in the Netherlands (2007-2016) from the National Intensive Care Evaluation (NICE) quality registry (100\% coverage of adult ICUs in 2016; population size 14 million) to calculate SARI incidence, SARI peak levels, ICU SARI mortality, SARI mean Acute Physiology and Chronic Health Evaluation (APACHE) IV score, and the ICU SARI/ILI ratio. These parameters were calculated both yearly and per separate influenza epidemic (defined epidemic weeks). A SARI syndrome was defined as admission diagnosis being any of six pneumonia or pulmonary sepsis codes in the APACHE IV prognostic model. Influenza epidemic periods were retrieved from primary care sentinel influenza surveillance data.
\end{abstract}

Results: Annually, an average of 13\% of medical admissions to adult ICUs were for a SARI but varied widely between weeks (minimum 5\% to maximum 25\% per week). Admissions for bacterial pneumonia (59\%) and pulmonary sepsis (25\%) contributed most to ICU SARI. Between the eight different influenza epidemics under study, the value of each of the severity parameters varied. Per parameter the minimum and maximum of those eight values were as follows: ICU SARI incidence 558-2400 cumulated admissions nationwide, rate 0.40-1.71/10,000 inhabitants; average APACHE score 71-78; ICU SARI mortality 13-20\%; ICU SARI/ILI ratio 8-17 cases per 1000 expected medically attended ILI in primary care); peak-incidence 101-188 ICU SARI admissions in highest-incidence week, rate 0.07-0.13/10,000 population).

Conclusions: In the ICU there is great variation between the yearly influenza epidemic periods in terms of different influenza severity parameters. The parameters also complement each other by reflecting different aspects of severity. Prospective syndromic ICU SARI surveillance, as proposed by the World Health Organization, thereby would provide insight into the severity of ongoing influenza epidemics, which differ from season to season.

Keywords: Severe acute respiratory infections, SARI, Intensive care, Influenza, Pneumonia, Severity, Burden

\footnotetext{
* Correspondence: liselotte.van.asten@rivm.nl

${ }^{1}$ Centre for Infectious Disease Control Netherlands, National Institute for

Public Health and the Environment (RIVM), Bilthoven, The Netherlands

Full list of author information is available at the end of the article
}

(c) The Author(s). 2018 Open Access This article is distributed under the terms of the Creative Commons Attribution 4.0 International License (http://creativecommons.org/licenses/by/4.0/), which permits unrestricted use, distribution, and reproduction in any medium, provided you give appropriate credit to the original author(s) and the source, provide a link to the Creative Commons license, and indicate if changes were made. The Creative Commons Public Domain Dedication waiver (http://creativecommons.org/publicdomain/zero/1.0/) applies to the data made available in this article, unless otherwise stated. 


\section{Introduction}

Though advocated by the World Health Organization (WHO) and the European Centre for Disease Prevention and Control (ECDC), surveillance of severe acute respiratory infections (SARI) that require hospital admission is implemented in only few Western European countries [1-4]. In contrast, surveillance of acute respiratory infections (ARI) or influenza-like illness (ILI) in primary care is well-established as part of the European Influenza Surveillance Network (EISN), coordinated by the ECDC $[5,6]$. Such primary care surveillance covers the community dwelling population and is thus focused on patients with milder illness. The number of patients developing serious complications and who require hospitalization is not available through this system and therefore, our understanding of the burden of respiratory infections is incomplete. The WHO recommends development and application of additional SARI measures that can be used to assess the severity of every influenza epidemic, whether seasonal or pandemic, and creating a historical SARI baseline [7]. The proposed measures include: SARI incidence, SARI peak levels, SARI mortality, and the SARI/ILI ratio. A SARI is a so-called syndrome group, i.e. based on rapidly available (initial) diagnoses that can be monitored as an indicator of infectious disease trends, outbreaks, and burden [8].

The most important complication of influenza virus infection is pneumonia (primary viral or secondary bacterial pneumonia) [9]. While costs can be high, the precise burden remains a blind spot [10-15]. Such burden information is crucial for prevention and response considering that vaccination, the main control measure against influenza infection, is aimed at preventing complications. A severe influenza season may also lead to hospital capacity problems, especially in ICUs. In this study we analyze comprehensive retrospective ICU data to fill the current knowledge gap.

\section{Methods}

We combined two databases (of ICU and ILI data) for the 2007-2016 time period.

\section{Intensive care data}

We used data from the National Intensive Care Evaluation (NICE) registry, which has registered adult ICU admissions for quality monitoring purposes [16, 17] since 1996. The coverage has increased over time reaching $90 \%$ coverage in 2012 and nearly $100 \%$ in 2016. Since 2007, all ICUs participating in the NICE registry have adopted the Acute Physiology and Chronic Health Evaluation IV (APACHE IV) model, which has more detailed diagnostic categories than the previous APACHE II model $[18,19]$.

We used weekly data on number of participating ICUs, number of medical ICU admissions (i.e. excluding admissions for surgery or for trauma), number of ICU SARI admissions (total and per APACHE IV diagnosis code), mean score from the APACHE IV model, in-ICU mortality, and age group. APACHE scores are commonly used in ICUs to quantify the severity of the illness of the patients (the higher the score the more severely ill), and to adjust for severity of illness when comparing outcome (mortality, length of stay) of different populations of patients [19].

We defined a syndrome group for ICU SARI admissions by including any respiratory diagnosis that could potentially have been of an infectious origin, i.e. caused by a respiratory pathogen such as influenza. A patient was considered an ICU SARI admission when all three of the following criteria were met: (1) the patient was admitted to the hospital less than 2 days before ICU admission (to differentiate between community acquired versus nosocomial infection), (2) the ICU admission was not a readmission to the ICU within the hospitalized period, and (3) the APACHE IV reason for admission included any of the six respiratory codes for pulmonary sepsis or pneumonia (Table 2). Patients can have up to two APACHE IV codes registered upon admission. The NICE registry does not contain results of microbiological laboratory results.

\section{Influenza-like-illness data}

Influenza surveillance in the Netherlands is based on sentinel general practitioners (GPs) participating in the Nivel Primary Care database, actively reporting the weekly number of patients consulting them for ILI [20]. ILI is defined as (1) sudden onset of symptoms, (2) fever, and (3) at least one of the following symptoms: cough, rhinorrhoea, sore throat, frontal headache, retrosternal pain, or myalgia [21]. GPs also take swabs from a random subset of patients with ILI for virological examination to determine whether influenza virus is circulating in the general population [20]. Epidemic weeks were those weeks in which the overall ILI incidence exceeded the threshold of 5.1/10,000 persons for a minimum of 2 consecutive weeks, which is based on the moving epidemic method used by countries participating in EISN [22] (the prospective data having small differences with fully completed retrospective datasets [23, 24]). During the nine seasons in the study period there were eight influenza epidemics of varying duration (based on all age groups combined). While influenza was circulating and ILI incidence crossed the threshold twice but not in consecutive weeks, retrospectively there was no influenza epidemic in $2011 / 2012$. We further selected ILI in patients age 15 years and older, as only adult ICU admissions were available ( 15 years being the child/adult cutoff available in the ILI registry). We used season-years (which we defined as running from week 27 to week 26 in the next year) instead of calendar years, as respiratory pathogens circulate mostly in winter. 


\section{Population size data}

Data on the Dutch population size by age (1 January in each year) were extracted from the website of Statistics Netherlands (www.cbs.nl).

\section{Analyses}

We described incidence of ICU SARI admissions during complete season-years and we described ICU SARI characteristics during defined influenza epidemics: incidence (cumulated over the epidemic weeks), rate (per 10,000 inhabitants), the contribution of the separate diagnoses to the syndrome, mean APACHE IV score, in-ICU SARI mortality, ICU SARI peak incidence (i.e. the highest registered weekly SARI incidence during an influenza epidemic), and the SARI/ILI ratio (the number of SARI per ILI case). All of these variables except for the APACHE score are proposed by the WHO. Characteristics were also stratified by age groups (15-44, 45-59, 60-64, and 65+ years). As the coverage increased over time, for comparison, we standardized the SARI incidences to the total number of medical ICU admissions in 2015/2016, when the NICE registry had near-complete national coverage. This was done by multiplying ICU SARI cases by the factor required to adjust the total number of medical admissions in each respective year to the total number of medical admissions observed in 2015/2016. The incidence of ILI was standardized to the size of the covered sentinel population of 2015/2016 (yearly coverage approximates $0.7 \%$ of the Dutch population, fluctuating slightly from year to year [20]). Due to the near-total coverage of the adult ICUs in 2015/2016 we used the standardized incidence and Dutch population-size data to calculate ICU SARI rates in the Dutch population. We estimated the ILI rates in the total adult Dutch population by extrapolating the coverage ( $\sim 0.7 \%)$ to the total Dutch population size (yearly). Time series were depicted graphically and we calculated coefficients (Pearson chi-squared or Spearman's rank where applicable) for correlation between time series.

\section{Results}

We first present overall yearly characteristics of SARI patients (irrespective of influenza epidemic weeks); second, we provide SARI characteristics specifically per influenza epidemic.

\section{Overall ICU SARI characteristics irrespective of influenza epidemic periods}

\section{Total ICU SARI admissions (irrespective of influenza} epidemics)

From January 2007 to December 2016 there were 588,571 registered ICU admissions, of which 257,589 (43.8\%) had a medical reason for admission, of which 33,007 (13\%) were SARI admissions in a total population size of 14 million adults in the Netherlands.
Year-to-year and week-to-week ICU SARI admissions (irrespective of influenza epidemics)

The overall proportion of ICU SARI admissions were relatively stable from one season-year to the next (11$14 \%$ of all ICU medical admissions were a SARI, Table 1), This proportion varied more from one week to the next (min 5\% to max 25\%) (standardized numbers are shown in Fig. 1, raw numbers in Additional file 1). The number of medical ICU admissions was higher when the number of ICU SARI admissions was higher (Spearman rank $R^{2}$ $0.79, p<0.001)$. The yearly rate of ICU SARI ranged from 2.74 to 3.35 per 10,000 inhabitants between the season-year (Table 1). The incidence was highest in the oldest age group (65+ years) and the proportion of ICU SARI admissions increased with increasing age (from an average $7 \%$ in $15-44$-year-olds to $15 \%$ in the $65+$ group). However, weekly, the highest proportion was in the 60 64 years age group reaching 36\% in season 2015/2016.

\section{Distribution of diagnoses in the ICU SARI-syndrome group (irrespective of influenza epidemics)}

The diagnoses contributing most to SARI admissions were those registered as "Pneumonia, bacterial" (59\% of SARI) and "sepsis, pulmonary" (25\%) (Table 2, with a figure of weekly trends per diagnosis shown in Additional file 2) and proportions were slightly lower in 15-44-year-olds than in the older age groups. The distribution varied somewhat from season-year to season-year, most notably for "Pneumonia, viral" (1-11\%) and for "Pneumonia, bacterial" (56-65\%) and the proportions are shown in a table in Additional file 3. The proportion of "Pneumonia, viral" increased with decreasing age (registered in $3.5 \%$ of people age $65+$ up to $8.5 \%$ of $15-44$-year-olds) and "Pneumonia, aspiration" was relatively more common in the youngest group ( $18 \%$ of $15-44$-year-olds vs $11 \%$ overall, Table 2 ).

\section{Clinical severity: APACHE IV score and in-ICU mortality (irrespective of influenza epidemics)}

While the number of ICU SARI admissions always peaked in winter, the weekly average APACHE IV score in the patients admitted was relatively stable and did not show winter peaks (Additional file 1). This was also confirmed by low correlation between the two $\left(R^{2} 0.04\right.$, $p$ value 0.41 ). Mortality in SARI within the ICU did show seasonality, with higher mortality in winter, visually coinciding with peaks in SARI admissions $\left(R^{2} 0.64, p\right.$ value $<0.0001$ ) (Fig. 1).

\section{ICU SARI characteristics during influenza epidemics ICU SARI admissions during influenza epidemics}

The standardized ICU SARI incidence during the eight influenza epidemics varied between 558 (in 2013/2014) and 2400 (in 2014/2015; the latter being the longest registered influenza epidemic in the Netherlands, lasting 


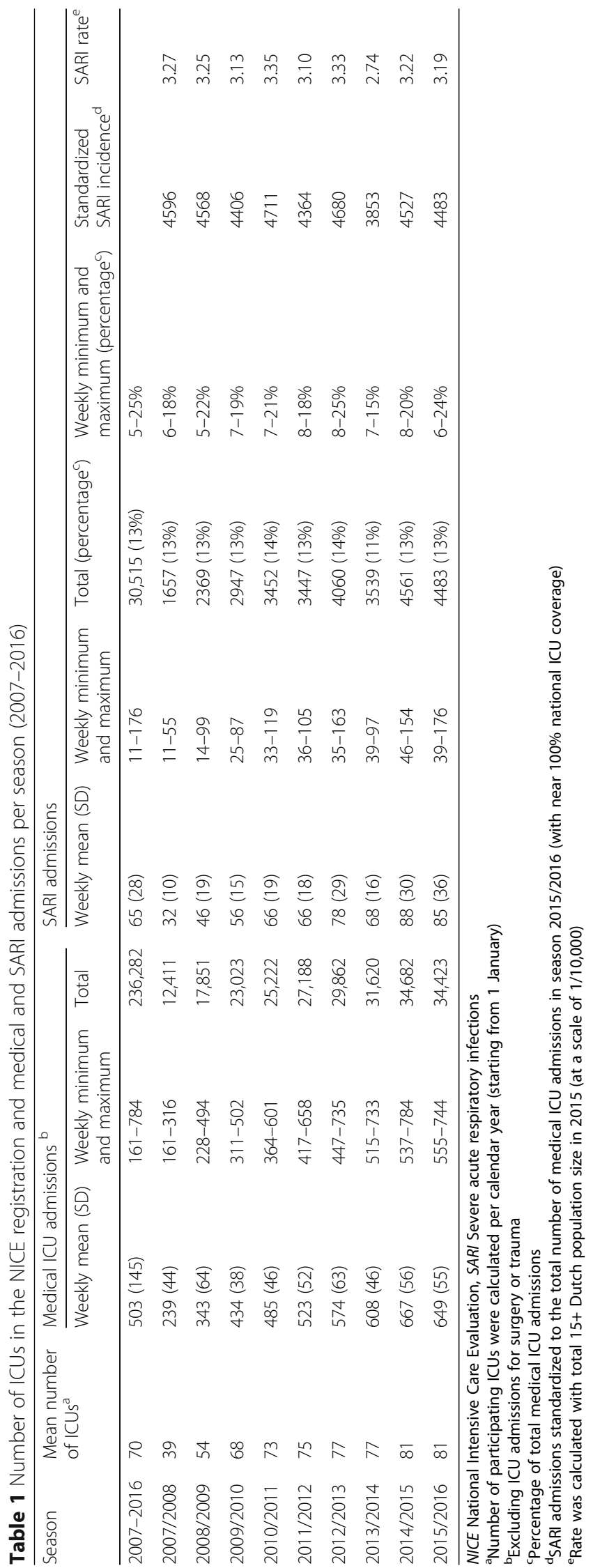




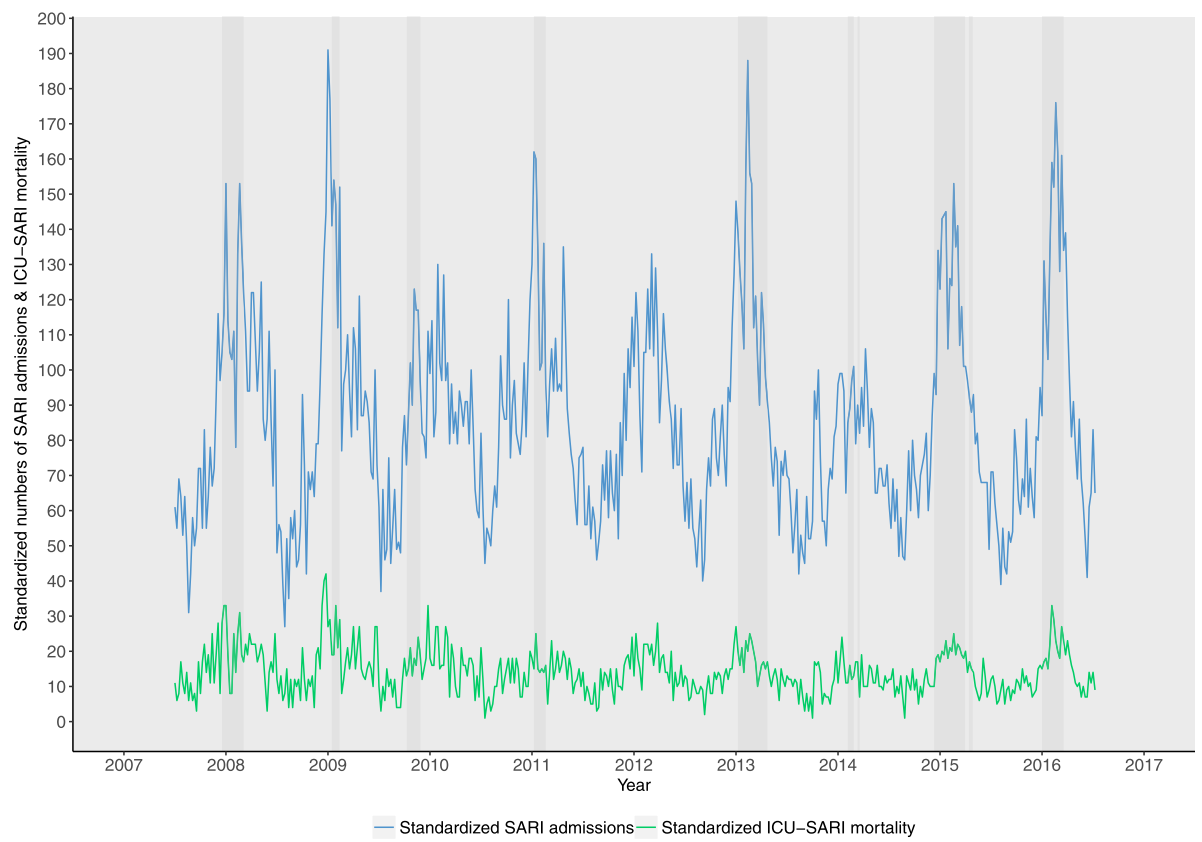

Fig. 1 Standardized number of severe acute respiratory infections (SARI) admissions and standardized in-ICU SARI mortality per year (all ages combined) (grey shading: influenza epidemic weeks)

20 weeks). Peak weekly incidence of ICU SARI varied by epidemic, with between 101 and 188 SARI admissions (in the 2013/2014 and 2012/2013 epidemic, respectively, standardized) or expressed as rates, $0.07-0.13 / 10,000$ inhabitants in the peak week. The week number in which this peak occurred varied widely per epidemic (between week 45 and week 8) and the timing within the epidemic varied (occurring at the beginning, middle, or end of an influenza epidemic (Table 3). By influenza epidemic, the ICU SARI rate varied between 0.40 and 1.71 per 10,000 inhabitants.

\section{The relationship between ICU SARI and ILI incidence during influenza epidemics (ICU SARI/ILI ratio)}

The three long epidemics of 2012/2013, 2014/2015, and 2015/2016 (12-20 weeks) showed high incidence of both ILI and of ICU SARI (Table 3). The ratio between the ICU SARI incidence and ILI incidence varies by influenza epidemic and lies between 1.3 and 2.7. This means that with every actual observed adult case of ILI in the sentinel surveillance (covering only $0.7 \%$ of the Dutch population) there were on average 1.3-2.7 observed ICU SARI admissions (covering the total adult ICU population). This ratio was lowest in 2009/2010 (the A(H1N1)pdm09 pandemic season) and highest in the 2007/2008 epidemic (Table 3). Using rates to calculate the SARI/ILI ratio, this translated to 0.008-0.017 ICU SARI admissions per estimated GP-attended ILI in the Dutch population (Table 4). In other words, per influenza epidemic, the estimated ILI rate in the total Dutch population was 59 -fold to 125 -fold higher than the ICU SARI rate. For example, in the 2015/2016 influenza epidemic there

Table 2 Proportion of SARI admissions to ICU by APACHE IV diagnosis by age group (in years) (2007-2016)

\begin{tabular}{|c|c|c|c|c|c|}
\hline APACHE reason for admission & Age $15-44$ & Age $45-59$ & Age 60-64 & Age $65+$ & All ages \\
\hline Sepsis, pulmonary & $20.51 \%$ & $24.54 \%$ & $25.86 \%$ & $25.84 \%$ & $25.11 \%$ \\
\hline Pneumonia, aspiration & $18.50 \%$ & $11.53 \%$ & $9.10 \%$ & $10.39 \%$ & $11.20 \%$ \\
\hline Pneumonia, bacterial & $49.46 \%$ & $57.24 \%$ & $60.36 \%$ & $60.71 \%$ & $58.97 \%$ \\
\hline Pneumonia, fungal & $0.47 \%$ & $0.52 \%$ & $0.47 \%$ & $0.27 \%$ & $0.36 \%$ \\
\hline Pneumonia, other & $13.00 \%$ & $12.05 \%$ & $12.70 \%$ & $11.66 \%$ & $11.98 \%$ \\
\hline Pneumonia, parasitic (i,e, Pneumocystis pneumonia) & $1.26 \%$ & $0.77 \%$ & $0.53 \%$ & $0.36 \%$ & $0.54 \%$ \\
\hline Pneumonia, viral & $8.51 \%$ & $6.36 \%$ & $5.12 \%$ & $3.45 \%$ & $4.68 \%$ \\
\hline
\end{tabular}

SARI Severe acute respiratory infections, APACHE Acute Physiology and Chronic Health Evaluation 


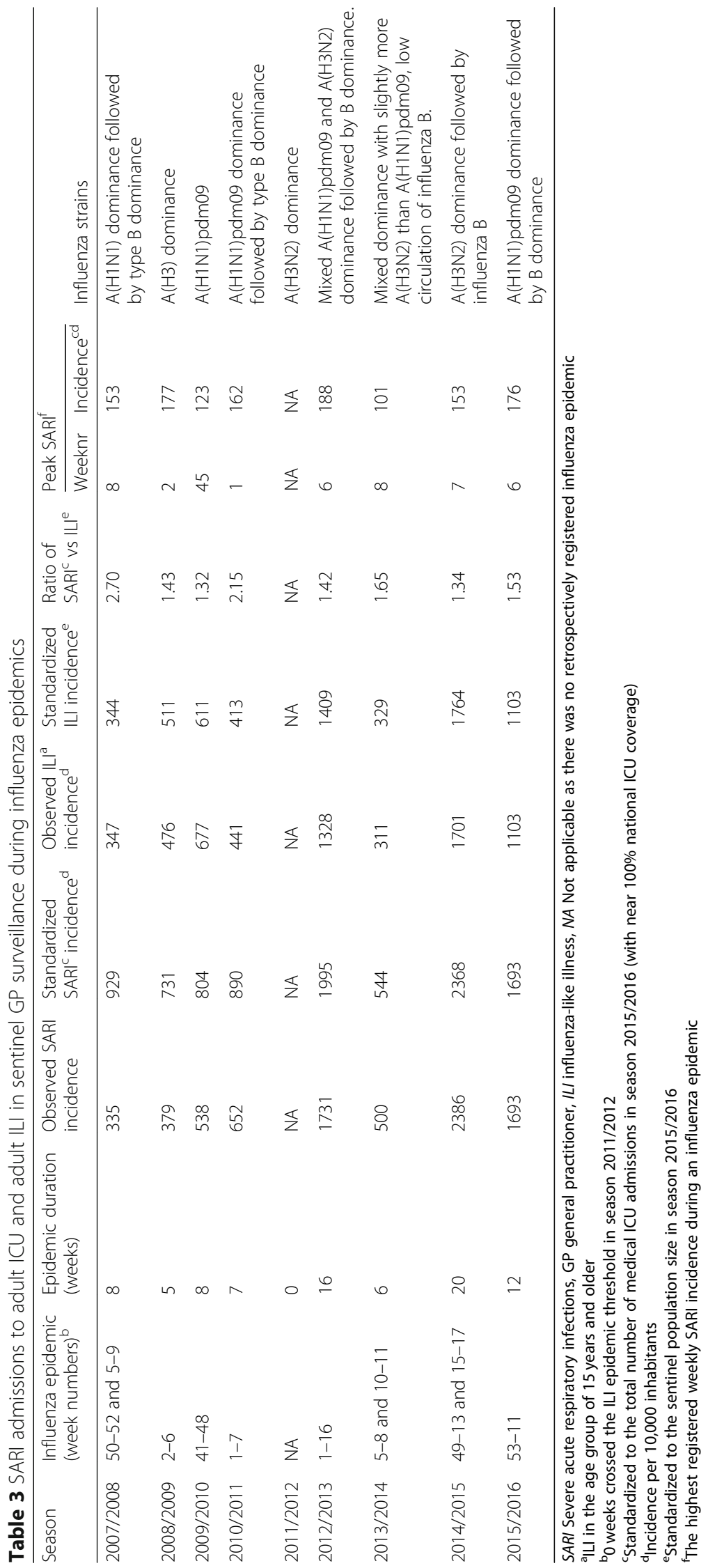


Table 4 SARI in ICU and ILI rates in the Dutch adult population during influenza epidemics

\begin{tabular}{|c|c|c|c|c|c|c|c|c|}
\hline \multirow[t]{2}{*}{ Season } & \multirow{2}{*}{$\begin{array}{l}\text { Total Dutch } \\
\text { population size } \\
\text { (aged } 15+\text { years) }^{\text {a }}\end{array}$} & \multirow{2}{*}{$\begin{array}{l}\text { Influenza } \\
\text { epidemic (week } \\
\text { numbers) }\end{array}$} & \multirow{2}{*}{$\begin{array}{l}\text { Epidemic } \\
\text { duration } \\
\text { (weeks) }\end{array}$} & \multirow{2}{*}{$\begin{array}{l}\text { SARI } \\
\text { rate }^{b}\end{array}$} & \multirow{2}{*}{$\begin{array}{l}\text { ILI } \\
\text { rate }^{\text {b }}\end{array}$} & \multirow{2}{*}{$\begin{array}{l}\text { SARI to } \\
\text { ILI ratio }\end{array}$} & \multicolumn{2}{|l|}{ Peak SARI $^{d}$} \\
\hline & & & & & & & Week number & peak SARI rate \\
\hline $2007 / 2008$ & $13,399,377$ & $50-52$ and 5-9 & 8 & 0.66 & 37.82 & 0.017 & 8 & 0.11 \\
\hline 2008/2009 & $13,469,675$ & $2-6$ & 5 & 0.52 & 56.18 & 0.009 & 2 & 0.13 \\
\hline 2009/2010 & $13,562,729$ & $41-48$ & 8 & 0.57 & 68.91 & 0.008 & 45 & 0.09 \\
\hline $2010 / 2011$ & $13,662,078$ & $1-7$ & 7 & 0.63 & 49.17 & 0.013 & 1 & 0.12 \\
\hline $2011 / 2012$ & $13,748,724$ & NA & 0 & NA & NA & NA & NA & NA \\
\hline $2012 / 2013$ & $13,833,689$ & $1-16$ & 16 & 1.42 & 147.79 & 0.010 & 6 & 0.13 \\
\hline $2013 / 2014$ & $13,901,653$ & 5-8 and 10-11 & 6 & 0.39 & 38.2 & 0.010 & 8 & 0.07 \\
\hline $2014 / 2015$ & $13,979,215$ & 49-13 and 15-17 & 20 & 1.68 & 194.16 & 0.009 & 7 & 0.11 \\
\hline $2015 / 2016$ & $14,073,660$ & $53-11$ & 12 & 1.2 & 115.41 & 0.010 & 6 & 0.13 \\
\hline
\end{tabular}

SARI Severe acute respiratory infections, GP general practitioner, ILI influenza-like illness, NA Not applicable as there was no retrospectively registered influenza epidemic ${ }^{a}$ Given for January-December of the first mentioned year of each season-year

${ }^{\mathrm{b}}$ Rate was calculated with total 15+ Dutch population size in 2015 (at a scale of 1/10,000)

'Number of ICU SARI per expected medically attended ILI in the total adult Dutch population

${ }^{\mathrm{d}}$ The highest registered weekly SARI incidence during an influenza epidemic

were 1693 adult ICU SARI admissions and an estimated total of 162,418 adult medically attended ILI cases in the total Dutch population (or 0.01 ICU SARI per estimated ILI).

The dominant circulating influenza strain(s) varied between the epidemics with H1N1, H3N2, mixed H1N1\&H3N2, and mixed domination with influenza B occurring in the study period (Table 3). The SARI incidence and the SARI/ILI ratio did not appear to depend clearly on the dominant subtype.

\section{APACHE IV score during influenza epidemics}

On average the mean score from the APACHE IV model (higher scores corresponding to more severe illness) varied between 71 and 78 between the epidemics and was usually higher with increasing age (Additional file 4) (note that age is factored into the score). The 2007/2008 epidemic was an exception, with the inverse being observed in the youngest three age-groups. The average APACHE IV score per influenza epidemic varied most in the youngest age group at $51-74$ (2010/2011 and 2007/2008), and varied least in the $65+$ age group at $77-82(2013 / 2014$ and 2009/2010 respectively) (see Additional file 4 for a table of these scores); the order by season mostly did not coincide in the different age groups.

\section{In-ICU mortality during influenza epidemics}

During the eight different influenza epidemics, the proportion of in-ICU deaths among all medical ICU admissions was $14-18 \%$. Among ICU SARI admissions the variation was slightly greater at between 13\% (2010/2011 epidemic) and 20\% (2007/2008 epidemic) (Additional file 4), and mortality usually increased with increasing age except in the $2007 / 2008$ epidemic when mortality was higher in the
15-44 year age group (16\%) than in the $45-59$ and $60-64$ year age-groups (12\%). Within the age groups, ICU SARI mortality also varied by epidemic: $2-16 \%$ in $15-44$-year-olds to $16-25 \%$ in the $65+$ age group. There was hardly any correlation between the proportion of ICU SARI deaths and the duration of the influenza epidemic $\left(R^{2}-0.12, p\right.$ value $0.78)$, the ICU SARI incidence (standardized) during epidemics $\left(R^{2}-0.12, p\right.$ value 0.78$)$, and the SARI/ILI ratio $\left(R^{2}-0.11, p\right.$ value 0.80$)$.

\section{Discussion}

This study helps to fill the knowledge gap on the burden of severe respiratory illness. It provides robust numbers on occurrence of ICU SARI and how these vary between the different influenza epidemics in the Netherlands. It shows how different parameters, proposed by the WHO for monitoring influenza severity [7], can vary greatly by season and that they complement each other: incidence, peak levels, ICU SARI mortality, mean APACHE IV score, and the ICU SARI/ILI ratio. They provide insight into different aspects of the severity of separate influenza seasons.

The ratio of ILI to ICU SARI admissions varied from influenza epidemic to influenza epidemic confirming that the intensive care burden of influenza is not predictable from ILI trends [25]. Depending on the epidemic, 8-17 SARI admissions occurred per 1000 cases of ILI in primary care (or a ratio of 1.3-2.7 ICU SARI admissions per each actual observed ILI in the $0.7 \%$ national ILI sentinel coverage).

Weekly medical ICU admissions were higher when SARI admissions were higher (Fig. 1) indicating that pressure on ICUs is expected to be higher in respiratory seasons. During the eight influenza epidemics under study, ICU 
SARI peaked at (min, max) 101 up to 188 ICU admissions in one week in the Netherlands. This is an almost twofold difference in peak-incidence between some seasons. Preparedness for severe or unusual seasons or outbreaks includes ICU capacity preparedness. The current situation in the Netherlands relies on crisis management when hospitals are to be overwhelmed. Whether and how often this occurs is not known due to lack of SARI surveillance. A SARI surveillance system might provide better insight into the location of potential bottlenecks and provide potential time gain allowing capacity planning instead of on-thespur crisis management.

For influenza severity assessment, monitoring a SARI syndrome instead of specific diagnoses would be of use as distinguishing between bacterial and viral causes of pneumonia is difficult and bacterial pneumonia is often secondary to viral infection [26-28]. Only $4.7 \%$ of the diagnoses are registered as viral pneumonia, which may be an underestimation: laboratory data are not yet available in the NICE registry, and the specific etiology of SARI cases could not be determined. Furthermore, laboratory testing for influenza virus or other respiratory viruses is not standard practice in hospitalized patients with SARI; less than half of patients admitted to the ICU with suspected pneumonia are tested [29]. Notably in our data, in the 2015/2016 season a large proportion of ICU SARI was registered as viral. Whether this is a true finding, a registration artifact, or whether more laboratory testing occurred in that year is not clear. Further, inherent to a syndromic surveillance approach based on rapidly available provisional data, a SARI syndrome may contain some patients with an incorrect initial diagnosis at admission. Another limitation is that no data were available on influenza vaccination status or use of oseltamivir.

In terms of the highest extremes, notable influenza epidemics are those of $2007 / 2008,2012 / 2013$, and 2014/ 2015 for different parameters. The 2014/2015 epidemic was the longest recorded ( 20 weeks) and corresponded with the highest ICU SARI and ILI incidence but not with highest values of other ICU SARI characteristics. The highest peak of ICU SARI (188 in one week, standardized) was in the 2012/13 epidemic (16-week-long epidemic). In contrast, the $2007 / 2008$ epidemic was much shorter (8 weeks) but had the highest ICU SARI/ ILI ratio as was also reported in the USA [30], and the largest proportion of deaths. These results may, however, potentially have been affected by the low ICU coverage in that first study year (around 50\%), although we do not know in which direction this may have impacted results.

In terms of the lowest extremes the 2009/2010 season was the pandemic season (A(H1N1)pdm09 circulation), known to have been milder in older people [31], showing the lowest ICU SARI/ILI ratio indicating a lower than average ICU burden per influenza infection in that year. The dominant virus in the following epidemic (2010/2011) was also influenza virus $\mathrm{A}(\mathrm{H} 1 \mathrm{~N} 1) \mathrm{pdm} 09$, showing no drift to the previous season and which coincided with the smallest proportion of in -ICU SARI deaths. The 2013/2014 season was a relatively short epidemic (6 weeks) with the lowest SARI peak and with the lowest incidence of both SARI and ILI.

As the most severe outcome of any disease, mortality data, if available, could provide an important indication of flu season severity. Mortality can be high in pneumonia hospitalizations, but to date the burden of influenza mortality remains uncertain and is estimated mostly from modeling studies [13, 32]. Fatal outcome may be more prevalent in influenza-positive SARI [3]. In our study, in-ICU mortality in patients with SARI during influenza epidemics varied between $13 \%$ and $20 \%$. To what extent this reflects differing severities of influenza seasons is not entirely clear because SARI can be caused by different respiratory pathogens, patients may die after their ICU or total hospital stay [33], and shifts in afflicted age groups can impact mortality numbers. In a German study, mortality in hospitalized patients with SARI (thus not only in the ICU) was lower (5-year-average 11\%), but also included non-flu weeks [2]. Future exploration of a more comprehensive mortality measure than in-ICU deaths (i.e. 30-day mortality or survival to hospital discharge) would improve the estimate of influenza impact.

An important strength of our study is that the coverage increased over time to include almost all adult ICUs in the country, thus providing a clear estimate of the total number and incidence of ICU SARI in the Netherlands. Comparing these with other Western European countries is difficult. Most countries do not have SARI surveillance and in those that do or those that have analyzed retrospective data, the SARI case definition varies due to different coding systems and the type of hospitalizations included (ICU, other wards) $[1,2]$. Additionally, criteria for ICU admission vary between countries, with Dutch ICUs being relatively restrictive. In Germany, retrospectively, ICU SARI admissions during influenza epidemics peaked at 17\% [2], in the range of the weekly peak of $15-25 \%$ that we observed in the different epidemics. Of hospitalized SARI in Belgium, influenza was laboratory-diagnosed in $46 \%$, and approximately $10 \%$ of SARI were in ICUs (sentinel surveillance of 2016/2017 epidemic) [1], similar to the $8-11 \%$ in ICUs in a Dutch pilot study in two hospitals [12] (Marbus S, et al: Acute respiratory infections in secondary care versus influenza-like illness in primary care in the Netherlands: hospital incidence peaks first, submitted). Although such estimates are not available from the national registry data (NICE) they give a rough indication that total SARI hospitalizations (when including non-ICU SARI) in the Netherlands could be around 10-fold higher than SARI in ICUs and that influenza can potentially play a large role in overall SARI admissions. Some other countries record laboratory- 
confirmed influenza infections in ICUs, but without tracking a denominator or testing practices, thus not providing estimates on total SARI burden [34-39].

\section{Conclusion}

This study provides robust estimates on SARI occurrence in the Netherlands based on comprehensive national ICU registry data (NICE). Influenza severity measures proposed by the WHO vary by influenza epidemic and cannot be deduced from ILI surveillance alone, thus emphasizing the potential use of a prospective SARI surveillance for assessing the burden of seasonal influenza.

\section{Additional files}

Additional file 1: Raw weekly numbers of admissions, APACHE IV score and mortality in adult ICUs (2007-2016). Footnote: gray shading: influenza epidemic weeks as derived from ILI sentinel surveillance data. (PDF $15 \mathrm{~kb}$ )

Additional file 2: Number of SARI admissions to the ICU by APACHE IV diagnosis (2007-2016). Footnote: diagnoses: sepsis, pulmonary; pneumonia, aspiration; pneumonia, bacterial; pneumonia, fungal; pneumonia, other; pneumonia, parasitic (i.e. pneumocystis pneumonia); pneumonia, viral. (PDF $18 \mathrm{~kb}$ )

Additional file 3: Distribution of SARI admissions to adult ICU by APACHE IV diagnosis codes per season (\%). (DOCX 47 kb)

Additional file 4: In-ICU mortality and APACHE IV scores among ICU admissions during influenza epidemics. Footnote: *0 consecutive weeks crossed the ILI epidemic threshold in season 2011/2012. (DOCX 50 kb)

\section{Abbreviations}

APACHE: Acute Physiology and Chronic Health Evaluation; ECDC: European Centre for Disease Prevention and Control; EISN: European Influenza Surveillance Network; GPs: General practitioners; ICU: Intensive care units; ILI: Influenza-like-illness; NICE: National Intensive Care Evaluation; SARI: Severe acute respiratory infections; WHO: World Health Organization

\section{Acknowledgements}

We thank Eric van der Zwan for preparing the aggregated NICE dataset and for support with data-management, and Jeroen Alblas for support with data management

\section{Informed consent}

Informed consent was not required.

\section{Funding}

This study was financed from the regular budget of the Centre for Infectious Disease Control made available by the Ministry of Health, Welfare and Sport, project number V/150207.

\section{Availability of data and materials}

The datasets generated and/or analyzed during the current study are not publicly available as they are part of a national registry for quality monitoring, but are available from the authors on reasonable request and with permission from the NICE registry.

\section{Authors' contributions}

LvA and WvdH conceived the idea and initiated the project. NdK and GD provided the data. ALP performed the analysis with the help of LVA. LVA drafted the first version of the manuscript. All authors participated in the interpretation of the results and critically reviewed the manuscript. All authors read and approved the final manuscript.

\section{Ethics approval}

Ethics approval was not required.

\section{Consent for publication}

Consent for publication was not required (no individual data used).

\section{Competing interests}

The authors declare that they have no competing interests.

\section{Publisher's Note}

Springer Nature remains neutral with regard to jurisdictional claims in published maps and institutional affiliations.

\section{Author details}

${ }^{1}$ Centre for Infectious Disease Control Netherlands, National Institute for Public Health and the Environment (RIVM), Bilthoven, The Netherlands. ${ }^{2}$ National Intensive Care Evaluation, Amsterdam, the Netherlands. ${ }^{3}$ Department of Intensive Care Medicine, University Medical Center, Utrecht University, Utrecht, Netherlands. ${ }^{4}$ Department of Intensive Care, Leiden University Medical Center, Leiden, the Netherlands. ${ }^{5}$ Nivel Primary Care Database - Sentinel Practices, Utrecht, the Netherlands. ${ }^{6}$ Department of Medical Informatics, Amsterdam UMC, Location AMC, Amsterdam Public Health Research Institute, Amsterdam, The Netherlands.

Received: 11 August 2018 Accepted: 22 November 2018 Published online: 19 December 2018

\section{References}

1. Scientific Institute of Public Health Belgium: Seasonal influenza surveillance Belgium - overview season 2016-20172017. Available from: https:// epidemio.wiv-isp.be/ID/diseases/SiteAssets/Pages/Influenza/ End\%20of\%20season\%202016-2017.pdf Accessed 18 May 2018.

2. Buda S, Tolksdorf $K$, Schuler E, Kuhlen R, Haas W. Establishing an ICD-10 code based SARI-surveillance in Germany - description of the system and first results from five recent influenza seasons. BMC Public Health. 2017; 17(1):612.

3. Meerhoff TJ, Simaku A, Ulqinaku D, Torosyan L, Gribkova N, Shimanovich V, et al. Surveillance for severe acute respiratory infections (SARI) in hospitals in the WHO European region - an exploratory analysis of risk factors for a severe outcome in influenza-positive SARI cases. BMC Infect Dis. 2015;15:1.

4. World Health Organization: Overview of sentinel systems for hospitalized severe acute respiratory infections (SARI) represented in the weekly EuroFlu surveillance bulletin (as of 10 February 2013)2013 18 July 2018. Available from: http://www.euro.who.int/_data/assets/pdf_file/0005/186863/ Overview-of-SARI-Surveillance-Systems-final.pdf Accessed 18 May 2018.

5. European Centre for Disease Prevention and Control: European Influenza Surveillance Network (EISN) 18 July 2018; 2017. Available from: https://ecdc. europa.eu/en/about-us/partnerships-and-networks/disease-and-laboratorynetworks/eisn Accessed 18 May 2018

6. Dijkstra F, Donker GA, Wilbrink B, Van Gageldonk-Lafeber AB, Van Der Sande MA. Long time trends in influenza-like illness and associated determinants in The Netherlands. Epidemiol Infect. 2009;137(4):473-9.

7. World Health Organization: Pandemic Influenza Severity Assessment (PISA): a WHO guide to assess the severity of influenza epidemics and pandemics2017 18 July 2018. Available from: http://www.who.int/influenza/ surveillance_monitoring/pisa/guidance/en/ Accessed 18 May 2018.

8. Triple S Project. Assessment of syndromic surveillance in Europe. Lancet (London, England). 2011;378:2.

9. Davis BM, Aiello AE, Dawid S, Rohani P, Shrestha S, Foxman B. Influenza and community-acquired pneumonia interactions: the impact of order and time of infection on population patterns. Am J Epidemiol. 2012;175(5):363-7.

10. Chalmers J, Campling J, Ellsbury G, Hawkey PM, Madhava H, Slack M. Community-acquired pneumonia in the United Kingdom: a call to action. Pneumonia (Nathan). 2017;9:15

11. Weinberger DM, Harboe ZB, Viboud C, Krause TG, Miller M, Molbak K, et al. Pneumococcal disease seasonality: incidence, severity and the role of influenza activity. Eur Respir J. 2014;43(3):833-41.

12. Teirlinck A, Van Asten L, Brandsema P, Dijkstra F, Donker G. Van GageldonkLafeber A, et al. In: Annual report surveillance of influenza and other respiratory infections in the Netherlands: Winter 2016/2017; 2017. Available from: https://www.rivm.nl/bibliotheek/rapporten/2017-0096.pdf. Accessed 18 May 2018.

13. van Asten $L$, van den Wijngaard C, van Pelt W, van de Kassteele J, Meijer A, van der Hoek W, et al. Mortality attributable to 9 common infections: 
significant effect of influenza A, respiratory syncytial virus, influenza B, norovirus, and parainfluenza in elderly persons. J Infect Dis. 2012;206(5):628-39

14. Vissink CE, Huijts SM, de Wit GA, Bonten MJ, Mangen MJ. Hospitalization costs for community-acquired pneumonia in Dutch elderly: an observational study. BMC Infect Dis. 2016;16:466.

15. Welte T, Torres A, Nathwani D. Clinical and economic burden of community-acquired pneumonia among adults in Europe. Thorax. 2012; 67(1):71-9.

16. Stichting NICE: Nationale Intensive Care Evaluatie 201718 July 2018; 2017(05-12). Available from: https://www.stichting-nice.nl/ Accessed 18 May 2018.

17. van de Klundert N, Holman R, Dongelmans DA, de Keizer NF. Data resource profile: the Dutch National Intensive Care Evaluation (NICE) Registry of Admissions to Adult Intensive Care Units. Int J Epidemiol. 2015;44(6):1850-h.

18. Knaus WA, Draper EA, Wagner DP, Zimmerman JE. APACHE II: a severity of disease classification system. Crit Care Med. 1985;13(10):818-29.

19. Zimmerman JE, Kramer AA, McNair DS, Malila FM. Acute Physiology and Chronic Health Evaluation (APACHE) IV: hospital mortality assessment for today's critically ill patients. Crit Care Med. 2006;34(5):1297-310.

20. Donker GA. NIVEL Primary Care Database - sentinel practices 2015201618 July 2018. Available from: https://www.nivel.nl/sites/default/files/bestanden/ Peilstations_2015_Engel.pdf. Accessed 18 May 2018.

21. Pel J. Proefonderzoek naar de frequentie en de aetiologie van griepachtige ziekten in de winter 1963-1964. Huisarts en Wetenschap. 1965:8:321-24. Available from: https://www.henw.org/files/download/1965_September_ Article_05.pdf

22. Vega T, Lozano JE, Meerhoff T, Snacken R, Mott J, Ortiz de Lejarazu R, et al. Influenza surveillance in Europe: establishing epidemic thresholds by the moving epidemic method. Influenza Other Respi Viruses. 2013;7(4):546-58.

23. P.S. Brandsema FD, S.M. Euser, A.B. van Gageldonk-Lafeber, M.M.A. de Lange, A. Meijer, E. Slump, B.E.P. Snijders, W. van der Hoek. Jaarrapportage surveillance respiratoire infectieziekten 2011. Rijksinstituut voor Volksgezondheid en Milieu (RIVM); 2012.

24. Donker GA. Continue Morbiditeits Registratie Peilstations Nederland 20112012. Available from: https:/www.nivel.n//sites/default/files/bestanden/ Continue-Morbiditeits-Registratie-Peilstations-NL-2011.pdf. Accessed 18 May 2018.

25. Koetsier A, van Asten L, Dijkstra F, van der Hoek W, Snijders BE, van den Wijngaard CC, et al. Do intensive care data on respiratory infections reflect influenza epidemics? PLoS One. 2013;8(12):e83854.

26. Joseph C, Togawa Y, Shindo N. Bacterial and viral infections associated with influenza. Influenza Other Respi Viruses. 2013;7(Suppl 2):105-13.

27. Ruuskanen O, Lahti E, Jennings LC, Murdoch DR. Viral pneumonia. Lancet (London, England). 2011;377(9773):1264-75.

28. Beninca E, van Boven M, Hagenaars T, van der Hoek W. Space-time analysis of pneumonia hospitalisations in the Netherlands. PLoS One. 2017;12(7): e0180797.

29. van Someren Greve F, Ong DS, Cremer OL, Bonten MJ, Bos LD, de Jong MD, et al. Clinical practice of respiratory virus diagnostics in critically ill patients with a suspected pneumonia: a prospective observational study. J Clin Virol. 2016;83:37-42

30. Benoit SR, Burkom H, McIntyre AF, Kniss K, Brammer L, Finelli L, et al. Pneumonia in US hospitalized patients with influenza-like illness: BioSense, 2007-2010. Epidemiol Infect. 2013;141(4):805-15.

31. Wijngaard CC, Asten L, Koopmans MP, Pelt W, Nagelkerke NJ, Wielders CC, et al. Comparing pandemic to seasonal influenza mortality: moderate impact overall but high mortality in young children. PLoS One. 2012;7(2):e31197.

32. Vestergaard LS, Nielsen J, Krause TG, Espenhain L, Tersago K, Bustos Sierra N, et al. Excess all-cause and influenza-attributable mortality in Europe, December 2016 to February 2017. Euro Surveill. 2017;22(14).

33. Brinkman S, de Jonge E, Abu-Hanna A, Arbous MS, de Lange DW, de Keizer NF. Mortality after hospital discharge in ICU patients. Crit Care Med. 2013; 41(5):1229-36

34. Boddington NL, Verlander NQ, Pebody RG. Developing a system to estimate the severity of influenza infection in England: findings from a hospital-based surveillance system between 2010/2011 and 2014/2015. Epidemiol Infect. 2017;145(7):1461-70.

35. Bolotin S, Pebody R, White PJ, McMenamin J, Perera L, Nguyen-Van-Tam JS, et al. A new sentinel surveillance system for severe influenza in England shows a shift in age distribution of hospitalised cases in the post-pandemic period. PLoS One. 2012;7(1):e30279.

36. Bonmarin I, Belchior E, Bergounioux J, Brun-Buisson C, Megarbane B, Chappert $J \mathrm{~L}$, et al. Intensive care unit surveillance of influenza infection in
France: the 2009/10 pandemic and the three subsequent seasons. Euro Surveill. 2015;20(46)

37. Gubbels S, Krause TG, Bragstad K, Perner A, Molbak K, Glismann S. Burden and characteristics of influenza $A$ and $B$ in Danish intensive care units during the 2009/10 and 2010/11 influenza seasons. Epidemiol Infect. 2013; 141(4):767-75.

38. European Centre for Disease Prevention and Control: Risk assessment of seasonal influenza, EU/EEA, 2016-2017 - Update, 25 January 2017201718 july 2018. Available from: https://ecdc.europa.eu/sites/portal/files/media/en/ publications/Publications/Risk-assessment-seasonal-influenza-2016-2017update.pdf Accessed 18 May 2018.

39. World Health Organization \& European Centre for Disease Prevention and Control: Flu News Europe 18 july 2018; 2017(05-12). Available from: http:// flunewseurope.org/ Accessed 18 May 2018.

\section{Ready to submit your research? Choose BMC and benefit from:}

- fast, convenient online submission

- thorough peer review by experienced researchers in your field

- rapid publication on acceptance

- support for research data, including large and complex data types

- gold Open Access which fosters wider collaboration and increased citations

- maximum visibility for your research: over $100 \mathrm{M}$ website views per year

At BMC, research is always in progress.

Learn more biomedcentral.com/submissions 